REVESCO. Revista de Estudios Cooperativos

ISSN: $1885-8031$

http://dx.doi.org/10.5209/REVE.60988

\title{
Nuevo marco legal para el reconocimiento como organización de productores de frutas y hortalizas de entidades jurídico-empresariales ${ }^{1}$
}

\author{
Rosario Cañabate $\mathrm{Pozo}^{2}$
}

Recibido: 13 de junio de 2018 / Aceptado: 8 de julio de 2018

Resumen. La necesidad constatada de mecanismos de integración y de concentración de la producción en el sector agroalimentario aconseja reflexionar sobre la peculiaridad de las Organizaciones de Productores de Frutas y Hortalizas (en adelante OPFH), a raíz de la publicación del Real Decreto 532/2017, de 26 de mayo, por el que se regula el reconocimiento y funcionamiento de las Organizaciones de Productores del sector de Frutas y Hortalizas, con el que se adapta nuestra legislación al nuevo marco normativo de la Unión Europea. Dichas OPFH pese a que proporcionan múltiples ventajas, tanto para los productores de frutas y hortalizas como para la ordenación del mercado, sin embargo, no han logrado todavía el éxito esperado.

Del nuevo marco legal, y como objeto principal de estudio, se analizan los elementos vertebradores para su reconocimiento como OPFH destacando sus principales novedades, así como las carencias presentes en el mismo. En parte, tales carencias pueden considerarse motivadoras de la falta de consolidación plena de la figura, por lo que se ofrecen propuestas de mejora al recién instaurado régimen jurídico de las OPFH. En todo caso, las cooperativas se erigen como una forma jurídica muy adecuada para el logro de los objetivos asociados a la producción y comercialización en común por parte de los productores de frutas y hortalizas, como finalidad básica y esencial de las OPFH, aunque otras formas jurídicas de organización empresarial como las Sociedades Agrarias de Transformación (en adelante SAT) y las sociedades mercantiles puedan ser reconocidas, igualmente, como OPFH.

Palabras clave: Organización de Productores; Cooperativas; Sociedades Mercantiles; SAT; Secciones; Reconocimiento; Control Democrático.

Claves Econlit: K29; L23; P12; P13.

\section{[en] The new legal framework for the recognition as organization of fruit and vegetable producers of legal-business entities}

Abstract. The well-known need for production's integration and concentration mechanisms in the agri-food sector, advises to reflect on the peculiarity of Fruit and Vegetable Producers' Organizations (hereinafter OPFH). The Royal Decree 532 / 2017, of May 26, which regulates the recognition and operation of the Producers' Organizations of the Fruit and Vegetables sector, adapts our legislation to the new regulatory framework of the European Union. These OPFH, despite the fact that they provide

1 El presente trabajo se realiza en el marco del Proyecto de Investigación "Retos y oportunidades en los procesos de concentración e integración del sector agroalimentario", referencia P12-SEJ-2555. Consejería de Educación y Conocimiento, cuyo investigador principal es Carlos Vargas Vasserot.

2 Universidad de Almería, España

Dirección de correo electrónico: rcpozo@ual.es 
multiple advantages for both fruit and vegetable producers and for market management, have not yet achieved the expected success.

This paper analyzes the core elements for obtaining the recognition as OPFH, highlighting the main novelties as well as the deficiencies present in the new regulation. Shortcomings could be due to the lack of full consolidation of this organizational figure, and therefore some proposals for improvement are presented to the newly established legal regime of the OPFH. In any case, cooperatives are established as the most appropriate legal form for the achievement of the objectives associated to the joint production and commercialization by the fruit and vegetable producers, although other legal forms as Agrarian Transformation Societies (hereinafter SAT) and commercial companies can also be recognized as OPFH.

Keywords: Fruit and Vegetable Producers' Organizations; Cooperatives; Commercial Companies; Agrarian Transformation Societies; Sections; Recognition; Democratic control.

Sumario. 1. Introducción. 2. Reconocimiento de las OPFH. 3. Consideraciones finales. 4. Referencias bibliográficas.

Cómo citar: Cañabate Pozo, R. (2019) Nuevo marco legal para el reconocimiento como organización de productores de frutas y hortalizas de entidades jurídico-empresariales. REVESCO. Revista de Estudios Cooperativos, Primer Cuatrimestre, No 130, pp. 33-54. DOI: 10.5209/REVE.60988.

\section{Introducción}

El origen de las OPFH se encuentra ligado a la Unión Europea y al marco de la Organización Común de Mercados en el sector de frutas y hortalizas como pilar esencial de la Política Agraria Común (Reglamento CEE núm. 1035/1972, del Consejo de 18 de mayo). Como se sabe, a través de la Organización Común de los Mercados (OCM) se materializan las medidas de mercado contenidas en el ámbito de la Política Agraria Común (PAC), en orden, fundamental, a estabilizar los mercados, garantizar un nivel de vida equitativo a los agricultores, incrementar la productividad agrícola, garantizar la seguridad de los abastecimientos y asegurar al consumidor suministros a precios razonables (artículo 33 del Tratado Constitutivo de la Comunidad Económica Europea que delimitó los objetivos de la PAC y su necesaria instauración y artículo 39 del Tratado de la Unión Europea).

La unificación de las diferentes OCMs (Reglamento (CE) núm. 1234/2007, de 16 de noviembre de 2007), ha supuesto la existencia en la actualidad de una sola OCM para los productos agrarios (Reglamento (UE) núm. 1308/2013, del Parlamento Europeo y del Consejo, de 17 de diciembre de 2013, por el que se crea la organización común de mercados de los productos agrarios) $)^{3}$. Por lo tanto, es ahí donde se insertan las actuales OPFH que, tomando como punto de partida las tradicionales organizaciones de productores agrarios y sus uniones, han venido desarrollando una importante labor en orden a la producción y comercialización de tales productos.

En ese sentido conviene referir, aunque sea brevemente, el proceso acaecido con anterioridad a la referida unificación. Así, puede destacarse el Reglamento (CE) núm. 2200/1996, del Consejo de 28 de octubre de 1996, por el que en relación

3 El Reglamento (CE) núm. 1234/2007 del Consejo fue sustituido por el Reglamento (UE) núm. 1308/2013 del Parlamento y del Consejo, de 17 de diciembre de 2013 por el que se crea la Organización Común de Mercados de los productos agrarios y por el que se derogan los Reglamentos (CEE) núm. 922/1972, (CEE) núm. 234/1979, (CE) núm. 1037/2011 y (CE) núm. 1234/2007. 
con la Organización Común de Mercados en el sector de la fruta y hortaliza y en la línea del reforzar el papel de las organizaciones de productores acarreará la creación de un fondo operativo, germen de los actuales fondos y programas operativos de las OPFH, partiendo de la necesidad de agrupar la oferta de los productores de frutas y hortalizas, a través de las referidas organizaciones de productores que quedarán, también, obligadas a disponer de medios técnicos para el acondicionamiento de los productos y a garantizar una gestión comercial adecuada (Ferrer, 2001). Ello ante la constatación de una demanda cada vez más concentrada que conformara a las OPFH como un instrumento idóneo que permitirá reforzar la posición de los propios productores en el mercado (Anido, Garcia, Ouabouch, 2010; Ferrer, 2005) Con ese objetivo inicial, que puede considerarse igualmente válido en el momento presente ante la evidencia de una oferta no organizada suficientemente en un mercado global cada vez más competitivo, se dio paso a las OPFH reconociendo como tales a las originarias organizaciones de productores agrarios y sus uniones que cumplieran con las nuevas exigencias de la referida reglamentación europea (artículo 11 Reglamento (CE) núm. 2200/1996). Se establecerán así nuevos criterios para el reconocimiento de las OPFH, que centran la atención en lo relativo al número mínimo de socios y de volumen mínimo de la producción comercializable, así como de conocimiento exhaustivo de sus efectivos productivos (Galdeano, Jaén, y Molina, 2000: 507). Como se verá dichos elementos pueden considerarse esenciales, conforme al régimen jurídico vigente, para el reconocimiento de una entidad jurídica como $\mathrm{OPFH}^{4}$.

No obstante el proceso de reforma de la agricultura y de la propia PAC, en la línea de aumentar y de mejorar la competitividad del sector y de su orientación al mercado actualizando los instrumentos de la OCM de frutas y hortalizas, puso de manifiesto la insuficiencia de las organizaciones de productores para alcanzar los objetivos propuestos de concentración de la oferta e incluso la falta de interés de los propios productores para su integración en una organización de productores (Amat, 2007). Por ello, las sucesivas reformas acaecidas han estado marcadas grosso modo, y en lo referente a las OPFH, por la facilitación o flexibilización de los requisitos para su reconocimiento y, al mismo tiempo, por un mayor control de su funcionamiento en atención al cumplimiento de su finalidad.

La Agenda 2000 recogió las nuevas directrices de la PAC y se incluyó ahí la mejora de la comercialización de los productos de los agricultores europeos, algo a lo que las OPFH sirven como pieza esencial de su conformación (Álvarez-Coque, López García Usach, Ouabouch y Anido, 2012). Las sucesivas reformas de la PAC han supuesto nuevos cambios de orientación y de formas de financiar económicamente a la agricultura desde la $\mathrm{UE}^{5}$, hasta llegar al nuevo ciclo de

4 En aquel marco normativo, han de referenciarse la Orden Ministerial de 30 de abril de 1997, sobre reconocimiento de organizaciones de productores de frutas y hortalizas y la Orden Ministerial de 14 de mayo de 1997, sobre reconocimiento de organizaciones de productores de frutas y hortalizas. Las agrupaciones de productores agrarios de la Ley 29/1972 de 22 de julio pudieron ser homologadas como OPFH, conforme a las exigencias de la Reglamentación Comunitaria.

5 La del año 2003 supuso la reorientación de la producción a las necesidades del mercado frente a las tradicionales ayudas a la producción. A ello sirven las OPFH como pieza esencial de su conformación; o la revisión producida en el año 2008, en virtud de la cual las ayudas se vincularán al cumplimiento de los 
reforma iniciado a partir del año 2013 que, de forma sintética, fundamenta la necesidad de modernización y de simplificación de su política que culmina con la nueva PAC. En su reflejo lógico, la OCM de frutas y hortalizas ha tenido su propio proceso de reforma para adaptarse a las previsiones de la $\mathrm{PAC}^{6}$.

Así, la Comisión Europea dentro de la nueva PAC para el periodo 2014-2020 y en el ámbito de la actual OCM ha señalado las bases fundamentales de la referida política (Comisión Europea, 2016), en donde la producción y la comercialización de productos hortofrutícolas adquieren un protagonismo esencial ${ }^{7}$. En tal sentido, las OPFH son instrumentos relevantes para el sector de las frutas y hortalizas en el nuevo periodo referenciado (Sánchez, 2015), adquiriendo cada vez mayor protagonismo como entidades apropiadas y serviles para agrupar la oferta, mejorar el sector en diversos ámbitos (producción y comercialización) y para conservar y proteger el medio ambiente (Colom, Florensa, Plana, y Smoui, 2017: 213).

Por todo ello desde la UE, a través de la OCM para el logro de los objetivos de la PAC, las OPFH son pieza central en todo proceso de reforma hasta la OCM Única y de la propia evolución en los objetivos de la PAC. Ello ha tenido su reflejo jurídico para, tomando como base las líneas estratégicas del nuevo modelo de la PAC, conformar la actual reglamentación europea ${ }^{8}$ y, en consonancia con ella,

objetivos de la Organización Común del Comercio (http://www.mapama.gob.es/es/agricultura/temas/pac/historia-pac/default.aspx).

6 En tal sentido se referencia el Reglamento 1182/2007, del Consejo de 26 de septiembre de 2007, por el que se establecieron disposiciones específicas para el sector de las frutas y hortalizas y el Reglamento 1580/2007 de la Comisión, de 21 de diciembre de 2007. Ambos Reglamentos modificaron la normativa comunitaria en materia de reconocimiento de OPFH y determinaron su desarrollo por los propios Estados miembros. Así, en nuestro ámbito nacional obedeció el Real Decreto 1972/2008, de 28 de noviembre, sobre reconocimiento de organizaciones de productores de frutas y hortalizas que derogó la Orden Ministerial de 30 de abril de 1997, sobre reconocimiento de organizaciones de productores de frutas y hortalizas (disposición derogatoria única Real Decreto 1972/2007). Se publicó, también, la Circular de Coordinación núm. 37/2012, de 22 de noviembre de 2012, sobre normas de coordinación para verificar las condiciones de reconocimiento de las OPFH. El Real Decreto 1302/2009 y, fundamentalmente, el Real Decreto 970/2014, de 21 de noviembre, modificaron el Real Decreto 1972/2008, de 28 de noviembre, sobre reconocimiento de organizaciones de productores de frutas y hortalizas.

7 Dentro de las líneas básicas de la estrategia UE 2020, que giran en torno a tres elementos fundamentales, crecimiento inteligente, crecimiento sostenible y crecimiento integrador de la agricultura, uno de los actuales retos económicos a los que las OPFH pueden servir es el relativo al mantenimiento del equilibrio de la cadena de valor de los productos agrarios y, en concreto, de las frutas y hortalizas. El productor agrario debe integrarse adecuadamente en la cadena agroalimentaria, que ha de ser más competitiva y equilibrada entre los propios productores agrarios y la industria agroalimentaria (Sánchez, 2015). Al respecto puede recordarse que, el sector agrícola en general y, en particular, las frutas y hortalizas se enfrentan al problema de la baja rentabilidad de su producción debido, entre otros aspectos, a las propias exigencias normativas derivadas de las UE en materia de producción y de comercialización (seguridad alimentaria, calidad de los productos, etc.), y a la propia fragmentación estructural del sector primario (Comunicación de la Comisión al Parlamento Europeo, al Consejo, al Comité Económico y Social Europeo y al Comité de las Regiones, 2017).

8 Así, el Reglamento (UE) núm. 1308/2013, del Parlamento Europeo y del Consejo, de 17 de diciembre de 2013, por el que se crea la organización común de mercados de los productos agrarios y regula las organizaciones de productores y las asociaciones de éstas en los sectores agrícolas, estableciendo una serie de particularidades para el sector de las frutas y hortalizas. Dicho Reglamento deroga los Reglamentos (CEE) núm. 922/72, (CEE) núm. 234/79, (CE) núm. 1037/2001, y (CE) núm. 1234/2007. El Reglamento Delegado (UE) 2017, de la Comisión, de 13 de marzo de 2017, por el que se completa el Reglamento (UE) núm. 1308/2013 del Parlamento y del Consejo en lo que respecta a los sectores de las frutas y hortalizas y de las frutas y hortalizas transformadas, se completa el Reglamento (UE) núm. 1306/2013 del Parlamento Europeo y del Consejo en lo relativo a las sanciones que deben aplicarse en esos sectores y se modifica el Reglamento de Ejecución (UE) núm. 543/2011 de la Comisión. Y, el Reglamento de Ejecución (UE) 892/2017 de la Comisión, de 13 de marzo de 2017 por el que se establecen disposiciones de aplicación del Reglamento (UE) 
adaptar nuestra legislación en materia de OPFH. En tal sentido, han de destacarse el Real Decreto 532/2017, de 26 de mayo por el que se regula el reconocimiento y funcionamiento de las organizaciones de productores del sector de frutas y hortalizas y el Real Decreto 533/2017, de 26 de mayo por el que se regulan los fondos y programas operativos de las organizaciones de productores del sector de frutas y hortalizas ${ }^{9}$, como resultado de la necesaria adaptación de nuestro régimen jurídico a las nuevas exigencias de reconocimiento y funcionamiento de las OPFH introducidas en los Reglamentos Europeos.

Dicho escenario se ve ha visto afectado, recientemente, por la entrada en vigor el pasado 1 de enero de 2018, de los acuerdos alcanzados en materia agrícola en el marco del Reglamento Ómnibus ${ }^{10}$ y que modifica, entre otros Reglamentos de la PAC $^{11}$, el Reglamento (UE) 1308/2013, por el que se crea la Organización Común de los Mercados de los productos agrarios. Todo ello en la línea de simplificar, modernizar y flexibilizar la PAC, de reforzar la posición de los agricultores en la cadena de valor y de mejorar los instrumentos para la gestión de riesgos en la producción agraria (Garrancho, 2017). En tal contexto, se refuerzan las organizaciones de productores que, en lo que afecta al sector de las frutas y hortalizas, se materializa, fundamentalmente, con la introducción de nuevas medidas de prevención y de gestión de crisis en el ámbito de los programas operativos de las organizaciones de productores (Asaja, 2017) 12 $^{12}$ nuevas condiciones de reconocimiento y finalidades ${ }^{13}$, y con la ampliación de las excepciones de la PAC a las normas de defensa de la competencia ${ }^{14}$.

núm. 1308/2013, del Parlamento Europeo y del Consejo en los sectores de las frutas y hortalizas y de las frutas y hortalizas transformadas.

9 Ambas, en BOE núm.129, de 31 de mayo de 2017 y corrección de errores del Real Decreto 532/2017, en BOE núm. 65, de 15 de marzo de 2018. El Real Decreto 532/2017, de 26 de mayo, deroga el Real Decreto 1972/2008, de 28 de noviembre, sobre reconocimiento de organizaciones de productores de frutas y hortalizas (disposición derogatoria única Real Decreto 532/2017).

10 Reglamento (UE) 2017/2393 del Parlamento Europeo y del Consejo, de 13 de diciembre de 2017, publicado en DOUE de 29 de diciembre de 2017.

11 El Reglamento (UE) 2017/2393 modifica diferentes Reglamentos de la PAC: Reglamento (UE) 1305/2013, relativo a la ayuda al desarrollo rural a través del Fondo Europeo Agrícola de Desarrollo Rural; Reglamento (UE) 1306/2013, sobre financiación, gestión y seguimiento de la política agrícola común; Reglamento (UE) $1307 / 2013$, por el que se establecen normas aplicables a los pagos directos a los agricultores en virtud de los regímenes de ayuda incluidos en el marco de la política agrícola común; y, Reglamento (UE) 652/2014, por el que se establecen disposiciones para la gestión de los gastos relativos a la cadena alimentaria, la salud animal y el bienestar de los animales, y relativos a la fitosanidad y a los materiales de reproducción vegetal.

12 En concreto, se incluyen el asesoramiento a productores individuales o a otras organizaciones de productores o sus asociaciones (coaching), la constitución o reposición financiera de fondos mutuales y la diversificación y consolidación de mercados, así artículo 33 del Reglamento (UE) 1308/2013, conforme a modificación por el artículo 4.1 del Reglamento (UE) 2017/2393.

13 Se incluyen, entre las finalidades que persiguen las organizaciones de productores para su reconocimiento, la integración de alguna actividad, como puede ser la distribución o transformación conjunta, la organización conjunta el control de calidad, el uso conjunto de equipos e instalaciones de almacenamiento o, también, la adquisición conjunta de materias primas. Además, se podrán reconocer organizaciones de productores para más de un sector, cuando se cumplan las condiciones de reconocimiento de cada uno de los sectores para los que se solicita tal reconocimiento, así los artículos 152.1.b, y 154.1.bis del Reglamento (UE) 1308/2013, conforme a modificación operada por el artículo 4.10 y 11, respectivamente, del Reglamento (UE) 2017/2393.

14 Así, siempre que se contribuya a la consecución de los objetivos de la PAC (en la actual OCM no se debían comprometer los objetivos de la PAC) se podrán realizar negociaciones contractuales, planificar la producción de los socios, adaptar la oferta a la demanda, optimizar los costes de producción, comercializar y negociar en común los términos de los contratos de la totalidad o parte de la producción de sus miembros siempre, además, que se desarrolle alguna de las actividades, que se exigen para determinados, de forma genuina. 
De esa forma las OPFH, fieles a las ventajas asociadas a su instrumentación tanto para los productores de frutas y hortalizas como para la ordenación del mercado (Ventas, 2017), son pieza esencial de la regulación de los mercados agrarios, dentro del marco de la PAC y de acuerdo a las exigencias de la OCM, cuya consolidación demandada justifica el análisis jurídico del nuevo régimen para su reconocimiento como OPFH. Ello ante la necesidad constatada de mecanismos de integración y de concentración de la producción en el sector agroalimentario en general (Vargas, 2017), integrados dentro del marco de cooperación interempresarial (Mauleón Méndez, E., y Genovart Balaguer, 2016 y de Mauleón Méndez, 2015) y, en particular, en el propio de las frutas y hortalizas que reclama un régimen especial. En tal contexto, las OPFH se presentan como un instrumento adecuado para la ordenación de la producción de frutas y hortalizas, es decir para la planificación de su producción posibilitando la adaptación de la producción a las exigencias de la demanda a la que se responderá concentrando la oferta y comercializando conjuntamente los productores su producción, como vehículo orientador de los mercados y buena forma de estabilizarlos (Ferrer, 2001; Ferrer, 2005; Ventas, 2017).

\section{Reconocimiento de las OPFH}

El reconocimiento de las OPFH se encuentra regulado, fundamentalmente, en el artículo 4 del Real Decreto 532/2017, relativo a los requisitos de reconocimiento. Dicho precepto está al amparo de lo que se establece en el artículo 3 del Reglamento Delegado (UE) 2017/891, respecto de la personalidad jurídica de las entidades que pueden solicitarlo, conforme a lo dispuesto en el artículo 154 Reglamento (UE) núm. 1308/2013, que determina el reconocimiento de las organizaciones de productores.

A pesar de lo que a priori pudiera pensarse, por la apuesta desde la UE de la figura, sin embargo, los requisitos para el reconocimiento $y$, en su caso, mantenimiento no son fáciles de conseguir. Así, la existencia de un riguroso sistema de control respecto del mantenimiento de sus requisitos puede acarrear la suspensión e, incluso, la retirada del reconocimiento (artículos 24 y 25 Real Decreto 532/2017), amén, como se ha dicho, de las rigurosas exigencias legales para tal reconocimiento que ponen atención, especial, en evitar el reconocimiento de organizaciones de productores que obtengan los requisitos de reconocimiento mediante la creación de situaciones artificiales, artículo 4.3 del Real Decreto $532 / 2017$.

\footnotetext{
Además, pueden consultar a la Comisión, que deberá responder en un plazo de cuatro meses, sobre los acuerdos, decisiones y prácticas concertadas que se adopten, a fin de la determinación de su compatibilidad con las normas de defensa de la competencia. Se extiende a todas las organizaciones de productores reconocidas la posibilidad de planificar la producción y negociar contratos en nombre de sus miembros sin vulnerar las normas de defensa de la competencia.
} 


\subsection{Aspecto subjetivo y teleológico de las OPFH}

Se trata de determinar las entidades que pueden solicitar el reconocimiento como $\mathrm{OPFH}$ y las finalidades específicas u objeto para el que se crean.

A esos efectos, la OPFH carece como tal de personalidad jurídica y por ello ha de tratarse, en principio, de una entidad jurídica con personalidad jurídica reconocida. Dicha entidad jurídica será la que solicite el reconocimiento, por escrito, ante el órgano competente que determine la Comunidad Autónoma correspondiente a su domicilio social, para la categoría de organización de productores de que se trate, en éste caso, de frutas y/o hortalizas, artículos 4.1.e y 2.1 del Real Decreto 532/2017 ${ }^{15}$. Ahora bien, conforme al Reglamento (UE) 2017/2393, los diferentes estados miembros podrán conceder más de un reconocimiento a una misma organización de productores siempre que cumpla las exigencias de cada uno de los sectores para el que solicita el reconocimiento ${ }^{16}$.

La entidad que solicita el reconocimiento puede tratarse, además, de una parte claramente definida de una entidad jurídica, para el que se solicita el mismo reconocimiento como OPFH. En tal sentido, se abandonó su conformación sobre la base de una persona jurídica en exclusiva, conforme al Reglamento CE núm. 2200/1996 (Amat, 2007), para dar cabida a una entidad jurídica o, como establece de forma clara el artículo 4.1.a y g del Real Decreto 532/2017, acoger a sociedades mercantiles, cooperativas y SAT, para atender al requerimiento de tratarse de entidades con personalidad jurídica propia según el ordenamiento jurídico español. Conforme al artículo 3 del Reglamento Delegado (UE) 2017/891, compete a los diferentes Estados miembros de la UE definir las entidades jurídicas que, habida cuenta de sus estructuras jurídicas y administrativas, pueden solicitar el reconocimiento. La peculiaridad de la estructura jurídica de nuestras cooperativas (y, en su caso, grupo de productores de una SAT que constituya una sección que cumpla con los requisitos exigidos de la normativa reguladora de las secciones de las cooperativas y respete, al mismo tiempo, la suya propia) posibilita el reconocimiento como OPFH de la sección en la que se integrarán todos los productores de frutas y hortalizas que formen parte de la entidad jurídica de que se trate $^{17}$.

Respecto de las sociedades mercantiles se exige, expresamente, que las acciones o participaciones sociales, que conforman su capital social, sean nominativas, requisito éste que será extensivo a todos los miembros, directos o indirectos, de las

15 Las diferentes categorías para el reconocimiento están previstas en el artículo 5 del Real Decreto 532/2017, a saber: (i) Frutas y hortalizas. (ii) Frutas. iii) Hortalizas. (iv) Productos destinados a la transformación. (v) Cítricos. (vi) Frutos de cáscara. (vii) Setas. (viii) Aromáticas y condimentos. (ix) Uva de mesa. (x) Melón. (xi) Cebolla. Cada una de ellas incluye los productos recogidos en el anexo III del Real Decreto 532/2017.

16 Vid., Artículo 4.11 del Reglamento (UE) 2017/2393, por el que se incluye un nuevo apartado 1.bis al artículo 154 del Reglamento (UE) 1308/2013. El artículo 4.1 del derogado Real Decreto 1972/2008, sobre reconocimiento de organizaciones de productores de frutas y hortalizas preveía tal reconocimiento respecto de "la categoría o las categorías" para las que se solicitase el mismo reconocimiento. Si bien, el artículo 5.1 del Real Decreto 532/2017, conforme a lo establecido en el artículo 4 del Reglamento Delegado (UE) 2017/891, suprimió tal posibilidad que ahora podrá ser acogida nuevamente.

17 El artículo 2.1 del Real Decreto 1972/2008, sobre reconocimiento de organizaciones de productores de frutas y hortalizas limitaba tal reconocimiento respecto de aquellas entidades con personalidad jurídica que lo solicitasen pero la reforma operada al mismo por el Real Decreto 970/2014, de 21 de noviembre permitió el reconocimiento como OPFH de partes claramente definidas de una persona jurídica. 
organizaciones de productores, que sean sociedades mercantiles, con independencia de la personalidad jurídica propia de la organización, artículo 4.1.g del Real Decreto 532/2017.

Dichas entidades (bien sean creadas ex novo a efectos de solicitar, con posterioridad, el reconocimiento como OPFH o, bien, se trate de una entidad con personalidad jurídica ya reconocida o de una sección) deben cumplir, además, una serie de exigencias previstas en el artículo 154.1 del Reglamento (UE) núm. 1308/2013. Entre ellas, han de cumplir los requisitos establecidos en el artículo 152.1 del Reglamento (UE) núm.1308/2013 que, de conformidad con la modificación operada por virtud del artículo 4.10 del Reglamento (UE) 2017/2393 al artículo 152.1.b del Reglamento (UE) núm. 1308/2013, exige su creación a iniciativa de los productores y la realización como mínimo de una de las siguientes actividades: "transformación conjunta, distribución conjunta, incluidas las plataformas de venta conjuntas o las de transporte conjunto, envasado, etiquetado y promoción conjuntos, organización conjunta del control de la calidad, uso conjunto de equipos o instalaciones de almacenamiento, gestión conjunta de los residuos directamente relacionados con la producción, adquisición conjunta de materias primas, cualquier otro tipo de actividades conjuntas de servicios destinados a realizar uno de los objetivos enumerados en la letra c) del presente apartado".

Las organizaciones de productores han de perseguir, además, una finalidad específica que, para el sector de las frutas y hortalizas, como mínimo puede tratarse de uno de los siguientes objetivos, según el artículo 160 del Reglamento (UE) núm. 1308/2013: 1) garantizar que la producción se planifique y se ajuste con arreglo a la demanda, sobre todo en lo referente a la calidad y a la cantidad; 2) concentrar la oferta y la comercialización de los productos de sus miembros, incluyendo la comercialización directa; 3) optimizar los costes de producción y los beneficios de las inversiones realizadas en respuesta a normas relativas al medio ambiente y al bienestar de los animales, y estabilizar los precios de producción ${ }^{18}$. Así, el artículo 4.1.h del Real Decreto 532/2017, respecto del cumplimiento de los requisitos exigidos en los Reglamentos relativos a las $\mathrm{OPFH}$ y la particularidad del sector de las frutas y hortalizas respecto de otras organizaciones de productores.

No obstante, partiendo de la voluntariedad por parte de los productores integrados en el sector de frutas y hortalizas de constituir una OPFH y de

18 El artículo 151.1.c del Reglamento (UE) 1308/2013, determina las finalidades específicas para las que se reconoce una organización de productores, que pueden consistir, además de alguna de las mínimas exigidas para las OPFH, en uno o más de los objetivos siguientes: "realizar estudios y desarrollar iniciativas en relación con métodos de producción sostenibles, prácticas innovadoras, competitividad económica y la evolución del mercado; promover la asistencia técnica y prestar este tipo de asistencia para la utilización de prácticas de cultivo y técnicas de producción respetuosas con el medio ambiente, así como de prácticas y técnicas de producción respetuosas con el bienestar de los animales; promover la asistencia técnica y prestar este tipo de asistencia para el uso de normas de producción, mejorar la calidad de los productos y desarrollar productos con denominación de origen protegida, indicación geográfica protegida o cubiertos por una etiqueta de calidad nacional; gestionar los subproductos y los residuos, en particular con el fin de proteger la calidad del agua, el suelo y el paisaje y preservar y fomentar la biodiversidad; contribuir a un uso sostenible de los recursos naturales y a la mitigación del cambio climático; desarrollar iniciativas en materia de promoción y comercialización; gestionar los fondos mutuales contemplados en los programas operativos para el sector de la fruta y de las hortalizas a que hacen referencia el artículo 31, apartado 2 del presente Reglamento y el artículo 36 del Reglamento (UE) núm. 1305/2013; proporcionar la asistencia técnica necesaria para la utilización de los mercados de futuros y de los sistemas de seguro". 
conformidad con lo establecido en el artículo 16 del Reglamento Delegado (UE) 891/2017, si bien las OPFH han de estar constituidas exclusivamente por productores se pueden admitir en la OPFH a miembros no productores (ya sean personas físicas o jurídicas), los cuales no deberán ser tenidos en cuenta a efectos del cumplimiento de los criterios para el reconocimiento. A esos efectos, el artículo 6 del Real Decreto 532/2017, sólo los admite en las OPFH cuya personalidad jurídica sea cooperativa o SAT. Así, en virtud de la habilitación a los Estados miembros de la UE para poder determinar las condiciones en las que personas no productores pueden ser miembros de una OPFH, cuando se trate de una sociedad mercantil o, en su caso, de una sección todos sus miembros habrán de ser productores de los productos para los cuales se solicita el reconocimiento como OPFH. Además, para dar cumplimiento a las exigencias del artículo 16 del Reglamento Delegado (UE) 891/2017, los miembros no productores no podrán participar en la toma de decisiones relativas al funcionamiento de la OPFH, ni en las que tengan incidencia con programas y fondos operativos, debiendo todo ello reflejarse en sus estatutos. Asimismo, cuando se trate de miembros agregadores de la misma personalidad jurídica, es decir cooperativas o SAT, éstos podrán contar con miembros no productores en idénticas condiciones señaladas, teniendo en cuenta que en ambos casos, es decir ya se trate de OPFH o de miembros agregadores de productores con miembros no productores, los componentes de sus órganos de gobierno deberán ser elegidos, exclusivamente, por sus miembros productores.

De esa manera se preserva el control de la OPFH en los propios productores, de los productos para los que se solicita el reconocimiento, como núcleo esencial que justifica la existencia de la figura (Ventas, 2017). Y es que, dentro de los mismos requisitos se exige que estén constituidas y controladas por productores y que sus estatutos prevean las normas que garanticen a los mismos el control democrático de la organización y de la toma de decisiones en la misma (artículo 152.1.a del Reglamento (UE) núm.1308/2013 con remisión al artículo 153.2.c del mismo Reglamento).

\subsection{Aspecto cuantitativo y funcional: número mínimo de miembros productores y de valor de producción comercializable}

Entre las exigencias requeridas por la Reglamentación europea, en el artículo 154.1 del Reglamento (UE) núm. 1308/2013, se determinan, asimismo, las siguientes: que la OPFH ha de contar con un número mínimo de miembros y/o abarcar un volumen o un valor de producción comercializable mínimos. Tales elementos serán fijados por cada Estado miembro, en su zona de actuación ${ }^{19}$; que la OPFH ofrezca suficientes garantías de que puede llevar a cabo adecuadamente sus actividades, tanto en lo relativo a la duración como a la eficacia y prestación de asistencia humana, material y técnica a sus asociados, y en caso pertinente, a la concentración

19 Conforme al Reglamento (UE) núm. 1308/2013, artículo 154.1.b, los Estados miembros determinarán el número mínimo de miembros de la $\mathrm{OPFH}$ y/o volumen o valor de producción comercializables mínimos, lo que aporta flexibilidad a cada Estado para su determinación, en atención a sus necesidades frente al régimen del Reglamento 2200/96, que debía decidirlo la Comisión asesorada del Comité de gestión de frutas y hortalizas. 
de la oferta; y que, finalmente, los estatutos de la OPFH sean conformes a tales exigencias.

Por ese orden, y conforme a lo dispuesto en el artículo 5 del Reglamento Delegado (UE) 891/2017, los artículos 7 y 8 del Real Decreto 532/2017 regulan el número mínimo de miembros productores y de valor de producción comercializable, así como la forma para determinar dicho valor de la producción comercializable por una $\mathrm{OPFH}$, respectivamente. En tal sentido, y pese a la complicación de su determinación, constituye un aspecto esencial por el propio sentido de la OPFH: aunar a tales productores para la comercialización de común de sus productos (Ventas, 2017). Su determinación queda al arbitrio de la legislación de cada Estado miembro, ofreciendo flexibilidad frente a la determinación por la Comisión a partir de la realidad de cada uno de ellos. Pero aun siendo así, se alzan voces que reclaman un número mínimo mayor de miembros productores que debiera haberse acogido en el Real Decreto 532/2017 ${ }^{20}$ y podría haberse pensado, también, en la opción de mantener igual número mínimo de miembros productores y aumentar el valor de la producción comercializable (Documento de Posición de las cooperativas de frutas y hortalizas de Bélgica, Alemania, Francia, Grecia, España, Italia y Polonia: "PAC post 2020 y el futuro Régimen Comunitario de Ayudas al Sector de las Frutas y Hortalizas", en http://www.agro-alimentarias.coop/ficheros/doc/05583.pdf).

El número mínimo de productores para las $\mathrm{OPFH}$ queda establecido en cinco para, en función de la Comunidad Autónoma de que se trate, exigir un mínimo de valor de producción comercializable vinculado al número de productores. En buena lógica, ha de ser diferente por la peculiaridad de los cultivos de frutas y hortalizas vinculados a unas determinadas zonas geográficas más que a otras y por los productores vinculados a tales producciones. No existe un número máximo de productores, pese a la complicación de la gestión de una OPFH con un número muy elevado de miembros, pero sí una graduación del mínimo valor de la producción comercializable en función de número de socios y de la Comunidad Autónoma de que se trate ${ }^{21}$. Se establecen, además, ciertos matices a la hora de concretarlo para evitar posibles fraudes. Así, en primer lugar, el número mínimo de miembros de las OPFH y de valor de la producción comercializable será el correspondiente a la Comunidad Autónoma en la que la OPFH posea la mayoría de

20 Recientemente, COAG (Coordinadora de Organizaciones de Agricultores y Ganaderos), en http://www.agronegocios.es/publicados- la-nueva-normatia-estatal-regula-los-fondos-programas-operativoslas-opfh-reconocidas/.

${ }^{21}$ Según lo establecido en el anexo IV del Real Decreto 532/2017, para las organizaciones de productores reconocidas para las categorías de frutas y hortalizas, en las zonas de Galicia, Asturias, Cantabria, País Vasco, Islas Baleares, Castilla y León, y Canarias se exigen un número mínimo de miembros y de valor de producción comercializable, conforme a lo que sigue:

Número mínimo de miembros:

Entre cinco y quince

Más de quince

-En las demás zonas, distintas de las antes referidas:

Número mínimo de miembros

Entre de cinco y quince

Entre dieciséis y cuarenta

Más de cuarenta
Mínimo valor producción comercializable:

$1.000 .000 €$

$500.000 €$

Mínimo valor producción comercializable

$3.000 .000 €$

$2.500 .000 €$

$1.500 .000 €$ 
los efectivos productivos medidos en hectáreas o valor de la producción comercializable y no los establecidos para la Comunidad Autónoma en la que las OPFH tenga su sede social ${ }^{22}$. Y, en segundo lugar, se establece un complejo sistema para el cómputo del número mínimo de miembros productores para, en aras de facilitar su logro, evitar situaciones ficticias ${ }^{23}$. Es por ello que, en virtud de lo dispuesto en el artículo 60 del Reglamento (UE) núm. 1306/2013, del Parlamento Europeo y del Consejo de 17 de diciembre de 2013, sobre la financiación, gestión y seguimiento de la Política Agrícola Común, no se reconocerá a ninguna organización de productores que haya obtenido los requisitos de reconocimiento mediante la creación de situaciones artificiales, y en concreto, "cuando un miembro, directo o indirecto, posea un porcentaje desproporcionadamente elevado de los efectivos productivos de la organización; considerándose como tal cuando posea más del 50 por cien de los efectivos productivos de la organización. No obstante, aun cuando se alcance dicho porcentaje, si se demuestra que no existe ningún abuso de poder o influencia por parte de ningún miembro no se considerará situación artificial", artículo 4.3.a del Real Decreto 532/2017.

En cuanto al cálculo del valor de la producción comercializable por una OPFH, “...será la suma de los siguientes valores asi determinados, basados en la documentación contable, de la entidad y de los productores: a) El valor de la producción comercializada por la entidad solicitante del reconocimiento procedente, exclusivamente, de la producción de los productores que formen parte de ella en el momento de solicitar el reconocimiento, que corresponda a los productos para los que solicita el reconocimiento, y b) El valor de la producción comercializada por los productores, de la producción obtenida exclusivamente en sus explotaciones, que formen parte de la entidad en el momento de solicitar el

22 Así, en los casos en los que una organización de productores posea parte de sus efectivos productivos en una Comunidad Autónoma en la que los mínimos exigidos no sean los máximos para la categoría de reconocimiento que se solicita, deberán cumplirse los mínimos establecidos para la Comunidad Autónoma en la que tenga la mayoría de los efectivos productivos medidos en hectáreas o valor de la producción comercializable. Y, en el caso de que una organización de productores posea todos sus efectivos productivos en una Comunidad Autónoma, y su domicilio social esté en otra diferente, deberá cumplir los mínimos establecidos para la comunidad autónoma donde estén sus efectivos productivos, artículo 7.1, in fine Real Decreto $532 / 2017$.

23 Grosso modo, una persona física o jurídica solo podrá ser computada, o tenida en cuenta para el cómputo de personas jurídicas, una única vez y, así, los miembros productores que sean personas físicas diferentes cada uno computará como uno (siempre que no estén vinculadas, conforme a lo dispuesto en el artículo 13 Real Decreto 532/2017). Si con ellos no se alcanza el número mínimo de miembros exigidos, se computarán los miembros que sean personas jurídicas, hasta alcanzar el mínimo exigido, y para ello se establecen la siguiente forma y secuencia: en primer lugar, los que sean productores no agregadores de productores, cada uno computará como uno si más del 50 por cien de su capital social, directa y/o indirectamente, está en posesión de personas físicas que no hayan sido ya computado como miembros productores conforme a lo ya establecido, o se hayan utilizado para computar otro miembro productor en virtud de lo establecido. En caso de que haya varios miembros de este tipo que al final de su cadena societaria estén integrados por una o más personas físicas coincidentes, el orden en que se aplicará a cada una de ellas lo dispuesto en el párrafo anterior, será el que elija la organización de productores. En segundo lugar, los que sean agregadores de productores, ellos no computarán, y en su lugar se establecen reglas especiales para su determinación, de conformidad con lo establecido en el artículo 7.2, b) $2^{\circ}$ Real Decreto 532/2017. 
reconocimiento que no haya sido comercializado a través de ella, referente a los productos para los que la entidad solicita el reconocimiento" 24 .

Respecto de la exigencia de ofrecer la OPFH suficientes garantías de que puede llevar a cabo adecuadamente sus actividades, tanto en lo relativo a la duración como a la eficacia y prestación de asistencia humana, material y técnica a sus asociados, y en caso pertinente, a la concentración de la oferta, el artículo 9 del Real Decreto 532/2017 detalla los aspectos relativos a la estructura, medios técnicos y humanos, y actividades que desarrolla la OPFH. Éste aspecto funcional adquiere verdadera relevancia ya que el correcto funcionamiento y el desarrollo adecuado de las finalidades para las que se constituye la $\mathrm{OPFH}$, en definitiva, tanto la amplitud como la eficacia de los servidos que presta deben ser las piezas esenciales respecto de la atracción voluntaria de los productores hacía una OPFH (Amat, 2007) y no sólo el atractivo de la financiación a través de los planes y programas operativos a los que las OPFH pueden acceder (Ventas, 2017), pese a su evidente importancia (Colom, Florensa, Plana y Smoui, 2017).

No obstante, el cumplimiento de tales exigencias admite excepciones. Así, el caso de la comercialización de productos con destino a la industria o que no requieran cumplimiento de normas de comercialización en cuyo caso no será necesario que la OPFH disponga de los medios técnicos previstos para la recogida, la clasificación, el almacenamiento y el acondicionamiento de la producción de sus miembros; también puede suceder que, el cumplimiento de los requisitos que exigen las normas de comercialización de tales productos se realice en las propias explotaciones de los miembros productores y que dicha producción sea vendida, en exclusiva, en subasta en cuyo caso podrá no disponerse de los medios relativos a la adaptación de la presentación de la producción a lo solicitado por el comprador de la mercancía en subasta, y al almacenamiento.

Pero sin duda, la flexibilización respecto del cumplimiento de tal exigencia es manifiesta al posibilitarse que los medios técnicos de la OPFH sean aportados por sus miembros, por filiales, por asociaciones de organizaciones de productores a las que pertenezcan o, en su caso, mediante externalización ${ }^{25}$.

Dicha externalización posibilita que, de conformidad con el artículo 155 del Reglamento (UE) núm. 1308/2013 y con el artículo 13 del Reglamento Delegado (UE) 2017/891, las actividades de la OPFH en cumplimiento de su finalidad o finalidades específicas -excepto la de producción-, sean realizadas por un tercero. Para ello se necesitará el acuerdo del órgano competente en función del tipo de entidad de que se trate y formalizar, por escrito, el correspondiente acuerdo de externalización $^{26}$. No obstante, como vimos anteriormente, en virtud de lo

24 De conformidad con lo establecido en el artículo 8 in fine, "Ambos valores responderán al periodo de referencia elegido por la organización dentro del establecido en la normativa estatal básica por la que se regulan los fondos y programas operativos de las organizaciones de productores de frutas y hortalizas, en virtud de los artículos 8.2 y 22 del Reglamento Delegado (UE) 2017/891, de la Comisión, de 13 de marzo de 2017. No obstante, será el periodo de los doce meses inmediatamente anteriores a la solicitud de reconocimiento en los casos en que los productores no hubieran producido durante el periodo de referencia".

25 La externalización se posibilitó en virtud de la modificación que se introdujo al Real Decreto 1972/2008, de 28 de noviembre, sobre reconocimiento de organizaciones de productores de frutas y hortalizas por el Real Decreto 970/2014, de 21 de noviembre, como consecuencia de la adaptación de tal régimen jurídico a las exigencias de los nuevos Reglamentos europeos.

26 De conformidad con lo establecido en el artículo 9.4 del Real Decreto 532/2017, “Las externalizaciones, ya sean las previstas en el artículo 10 o en el 13 Reglamento Delegado (UE) 2017/891, de la Comisión, de 13 de 
dispuesto en el artículo 60 del Reglamento (UE) núm. 1306/2013, del Parlamento Europeo y del Consejo de 17 de diciembre de 2013, sobre la financiación, gestión y seguimiento de la Política Agrícola Común, no se reconocerá a ninguna organización de productores que haya obtenido los requisitos de reconocimiento mediante la creación de situaciones artificiales, y en concreto, "cuando la organización tenga externalizada todas las actividades que puede externalizar", artículo 4.3.a del Real Decreto 532/2017, así como "cuando toda o gran parte de la producción comercializada por la organización de productores se venda ..... a entidades a los que se tenga externalizada alguna actividad", artículo 4.3.b del Real Decreto 532/2017. De ahí que, se exija un verdadero funcionamiento como $\mathrm{OPFH}$.

\subsection{Contenido de los Estatutos}

Finalmente, y así lo establece el artículo 4.1.d del Real Decreto 532/2017, el reconocimiento de una OPFH exige que sus estatutos sean acordes a tales exigencias establecidas $^{27} \mathrm{y}$, de forma específica para las $\mathrm{OPFH}$, de conformidad

marzo de 2017, deberán aprobarse por la asamblea general de la organización o por el órgano equivalente en función del tipo de personalidad jurídica que posea, así como plasmarse en acuerdos comerciales escritos que recojan, al menos, los siguientes aspectos: a) La identificación de las partes. b) Los medios o servicios que se contratan descritos de una manera precisa y clara, junto con el coste de los mismos y la forma de pago. c) En el caso de externalizaciones del artículo 13 del Reglamento Delegado (UE) 2017/891, de la Comisión, de 13 de marzo de 2017, además: $1^{\circ}$. El hecho de que la organización de productores será la responsable de garantizar la ejecución de los servicios contratados, y de que asume la gestión, el control y la supervisión globales del acuerdo comercial.

$2^{\circ}$. La facultad de la organización de productores para impartir instrucciones obligatorias sobre los servicios contratados y para poner fin al contrato en caso de incumplimiento de las obligaciones contraídas por la entidad contratada. $3^{\circ}$. Cláusulas detalladas por las que la entidad contratada se comprometa a remitir por escrito a la organización de productores la información que le permita evaluar y ejercer el control real sobre la actividad o actividades externalizadas, concretando el tipo de información y los plazos de remisión de la misma. En caso de que la actividad externalizada sea la comercialización, esta información deberá incluir, de las transacciones comerciales llevadas a cabo por la entidad contratada, el tipo de producto que va a vender, la forma de venta, la cantidad y el precio de cada operación de venta. $4^{o}$. En caso de que se externalicen los servicios detallados en el artículo 7 (b) del Reglamento Delegado (UE) 2017/891 de la Comisión, de 13 de marzo de 2017, relativos a la recogida, clasificación, almacenamiento y/o acondicionamiento de la producción de sus miembros, la entidad contratada deberá aportar el procedimiento mediante el cual identificará los productos de la organización durante el proceso contratado. d) La duración del contrato". Por su parte, el artículo 9.5 y 6 del Real Decreto 532/2017, regulan que, "5. En los casos contemplados en el punto $4^{\circ}$ de la letra c) del apartado anterior, la organización podrá vender su producción a la entidad prestataria del servicio, siempre que el órgano competente de la comunidad autónoma correspondiente autorice este tipo de ventas, previa comprobación de que la organización de productores cumple con todos los requisitos de reconocimiento". "6. Cuando una organización de productores externalice la transformación de uno o más productos a una entidad, se deberá cumplir, además, lo siguiente: a) El producto debe permanecer en todo momento bajo propiedad de la organización de productores.

b) Una vez que se haya transformado el producto, la organización de productores llevará a cabo la comercialización. c) En ningún caso la organización podrá vender un producto transformado a la misma entidad que efectuó la transformación, o a entidades participadas por ella".

27 Es decir, conforme al artículo 154.1 del Reglamento (UE) núm. 1308/2013, "Para ser reconocida por un Estado miembro, la organización de productores que lo haya solicitado deberá ser una entidad jurídica o ser parte claramente definida de una entidad jurídica que: a) cumpla los requisitos establecidos en el artículo 152, apartado 1, letras a), b) y c); b) cuente con un número mínimo de miembros y/o abarque un volumen o un valor de producción comercializable mínimos, que habrá de fijar el Estado miembro interesado, en su zona de actuación; c) ofrezca suficientes garantías de que puede llevar a cabo adecuadamente sus actividades, tanto en lo relativo a la duración como a la eficacia y prestación de asistencia humana, material 
con el artículo 160 del Reglamento (UE) 1308/2013, “...exigirán a sus miembros productores que comercialicen toda su producción a través de la organización de productores". El contenido mínimo de los estatutos, acorde a lo dispuesto en el artículo 153.1 y 2 del Reglamento (UE) núm. 1308/2013 ${ }^{28}$, se detalla en el anexo I del Real Decreto $532 / 2017^{29}$, en donde tal exigencia específica queda contemplada

y técnica a sus asociados, y en caso pertinente, a la concentración de la oferta; d) disponga de estatutos que sean conformes a lo dispuesto en las letras a), b) y c) del presente apartado".

28 Dentro del contenido de los estatutos, el artículo 153.1 y 2 del Reglamento (UE) núm. 1308/2013 dispone que “1. Los estatutos de una organización de productores obligarán en particular a los productores asociados a: a) aplicar las normas adoptadas por la organización de productores en materia de notificación de la producción, producción, comercialización y protección del medio ambiente; b) pertenecer a una sola organización de productores con respecto a un producto determinado de la explotación; no obstante los Estados miembros pueden establecer excepciones a esta condición en casos debidamente justificados, en los que los productores asociados posean dos unidades de producción distintas situadas en zonas geográficas diferentes; c) facilitar la información solicitada a efectos estadísticos por la organización de productores. 2. Los estatutos de una organización de productores deberán prever también lo siguiente: a) los procedimientos de fijación, adopción y modificación de las normas contempladas en el apartado 1, letra a); b) la imposición a los miembros de contribuciones financieras para la financiación de la organización de productores; c) las normas que garanticen a los productores asociados el control democrático de su organización y de las decisiones de esta; d) las sanciones por incumplimiento de las obligaciones estatutarias, en particular el impago de las contribuciones financieras o infracciones de las normas establecidas por la organización de productores; e) las normas relativas a la admisión de nuevos miembros y, en particular, un periodo mínimo de adhesión, que no puede ser inferior a un año; f) las normas contables y presupuestarias necesarias para el funcionamiento de la organización".

29 El anexo I, relativo a la documentación a adjuntar con la solicitud de reconocimiento, en el apartado A.3 relativo a todas las organizaciones de productores, regula el contenido mínimo de los estatutos (o reglamento de régimen interno en caso de secciones), que deberá contener:

“a) La finalidad especifica que persigan de las establecidas en el artículo 152.1 c) incisos i), ii), y iii) del Reglamento (UE) núm. 1308/2013, del Parlamento Europeo y del Consejo, de 17 de diciembre de 2013.

b) La exigencia a sus miembros productores de comercializar toda su producción de los productos para los que la organización esté, o vaya a ser reconocida, a través de la organización.

En el caso de que la organización autorice a sus miembros productores a realizar ventas de las recogidas en el artículo 12 del presente real decreto, deberán recoger dicha autorización y el compromiso de establecer el procedimiento de control mencionado en dicho artículo.

c) Las demás obligaciones a que se someten los miembros productores de manera precisa y clara, en particular:

i) Las de aplicar las normas adoptadas por la organización en materia de notificación de la producción, de producción, de comercialización, y de protección al medio ambiente.

ii) Pertenecer a una sola organización de productores para la misma categoría de reconocimiento.

iii) Facilitar la información que se les solicite a efectos estadísticos de la organización de productores.

iv) Las contribuciones financieras que se les impondrá para financiar la organización de productores.

v) El periodo mínimo de adhesión a la organización.

vi) El periodo de aviso previo para causar baja en la organización, y las cargas económicas que tendrá que abonar por ello, así como cualquier otro efecto a que dé lugar el hecho de causar baja en la entidad.

vii) Las sanciones por incumplimiento de las obligaciones estatutarias.

d) Los procedimientos mediante los que se fijarán, adoptarán, y modificarán las normas contempladas en el letra c) anterior, inciso i).

e) Las cooperativas o sociedad agraria de transformación, que puedan poseer miembros no productores, la exigencia de que éstos no podrán participar en la toma de decisiones relativas al funcionamiento de la organización de productores, y a los programas y fondos operativos establecidos en los artículos 32 y 33 del Reglamento (UE) núm. 1308/2013, del Parlamento Europeo y del Consejo, de 17 de diciembre de 2013.

f) Las normas que garanticen a sus miembros productores el control democrático de la organización de productores y de las decisiones de ella en todo tipo de acuerdos. A estos efectos, deberán recoger los derechos de voto y el capital social de los miembros así como el quórum necesario para la adopción de acuerdos. En caso de poseer miembros no productores, deberán recoger que estos no podrán participar en la toma de decisiones relativas al funcionamiento como organización de productores, y a los programas y fondos operativos establecidos en los artículos 32 y 33 del Reglamento (UE) núm.1308/2013, del Parlamento 
en el artículo 5.2 del Real Decreto 532/2017, salvada la excepcionalidad prevista en su artículo 12, relativa la comercialización de la producción fuera de la organización de productores.

Así, de conformidad con lo dispuesto en el artículo 12 del Reglamento Delegado (UE) 2017/891, relativo a la posibilidad de comercialización de la producción fuera de la organización de productores según las condiciones que establezca cada Estado miembro de la UE, el artículo 12 del Real Decreto $532 / 2017$ regula que, las OPFH podrán autorizar a cada uno de sus miembros a no comercializar a través de ella hasta un 10 por cien del volumen o del valor de la producción de dicho miembro, siempre que la entidad controle y disponga de un sistema de control que deje rastro de los controles realizados por la organización que garantice el cumplimiento de dicho límite ${ }^{30}$. Dicho porcentaje engloba las ventas directas a consumidores para sus necesidades personales, las ventas de productos para los que la organización esté reconocida pero que sean marginales en relación al volumen comercializado por ella, y las ventas de productos que por sus características no estén cubiertos normalmente por la actividad comercial de la organización.

De esa forma, la excepción al principio de unidad de comercialización de toda la producción a través de la OPFH (Amat, 2007) sólo admite hasta un máximo del 10 por cien el volumen o del valor de la producción de cada miembro concretando las modalidades y exigiendo mecanismos de control por parte de la OPFH que permitan el cumplimiento del referido límite.

Por la posibilidad de que el reconocimiento como OPFH recaiga en una sección, será el reglamento de régimen interno el que cumpla con tales exigencias que

Europeo y del Consejo, de 17 de diciembre de 2013, ni podrán participar en la elección de los órganos de gobierno.

No obstante, en el caso de cooperativas o secciones de ellas que estén amparadas por una norma jurídica que implique su funcionamiento democrático, no será necesario que recojan lo dispuesto en el apartado anterior. g) Las normas relativas a la admisión de nuevos miembros.

h) Compromiso de llevar, a partir de la fecha de reconocimiento, una contabilidad especifica para las actividades sometidas a reconocimiento, y las normas contables y presupuestarias necesarias para el funcionamiento de la organización. En caso de que sea una sección, la contabilidad de la entidad a la que pertenece la sección deberá permitir diferenciar la actividad de esta.

i) En el caso de ser una cooperativa o sociedad agraria de transformación con sección de frutas y hortalizas, o ser una sección de las previstas en la letra (a) del apartado 1 del artículo 1 del presente real decreto:

- El reglamento de régimen interno de la sección deberá recoger la prohibición de adoptar acuerdos contrarios a la ley, a los estatutos de la entidad a la que pertenece, o al interés general de dicha entidad, y

- Los estatutos de la cooperativa o de la sociedad agraria de transformación que posean sección de frutas y hortalizas deberán establecer que las decisiones relativas al reconocimiento, al funcionamiento y a las actuaciones como organización de productores, incluidas las relativas a la presentación y ejecución de programas operativos y constitución de los fondos operativos establecidos en los artículos 32 y 33 del Reglamento (UE) núm. 1308/2013, del Parlamento Europeo y del Consejo, de 17 de diciembre de 2013, serán directamente adoptadas por la asamblea de la sección.

j) En las organizaciones de productores que posean miembros no productores, que los componentes de sus órganos de gobierno deberán ser elegidos, exclusivamente, por los miembros productores".

30 El artículo 12.2 del Reglamento Delegado (UE) 2017/891, determinó el porcentaje de la producción de cualquier miembro productor comercializada fuera de la organización de productores, el cual no debe superar el 25 por cien en volumen o en valor, habilitando a los diferentes Estados miembros para que puedan fijar un porcentaje más bajo, como es el caso del Real Decreto 532/2017, artículo 12. Ese mismo porcentaje del 10 por cien era el previsto en el derogado Real Decreto 1972/2008, sobre reconocimiento de organizaciones de productores de frutas y hortalizas, artículo 8, relativo al porcentaje de ventas directas a consumidores, directamente en sus explotaciones o fuera de ellas. 
deberá recoger de manera expresa, además, "la prohibición de adoptar acuerdos contrarios a la ley, a los estatutos de la entidad a la que pertenece o al interés general de dicha entidad", artículo 4.1,f,1 $1^{\circ}$ del Real Decreto 532/2017 2 .

Dentro del contenido de los estatutos de las OPFH han de destacarse dos aspectos relevantes que afectan a su buen funcionamiento. Nos referimos, en concreto, al periodo mínimo de adhesión de los productores a la OPFH y al control de su funcionamiento democrático que, frente a otros elementos que conforman el contenido mínimo de los estatutos, adquieren especial significación.

En primer lugar, conforme al artículo 11.1 del Real Decreto 532/2017, dicho periodo mínimo de adhesión es de tres años (salvo causa motivada ajena a la voluntad de los miembros), aunque las OPFH pueden determinar un plazo inferior para parte de sus miembros, siempre que sus estatutos lo permitan y se respete el plazo del período mínimo de adhesión del artículo 6.1 del Reglamento Delegado (UE) 891/2017, que no podrá ser inferior a un año ${ }^{32}$. Además, respecto de dichos miembros productores cuyo periodo de adhesión sea inferior a tres años, se establecen ciertas limitaciones, por cuanto que: a) no deberán figurar en el registro que llevan las organizaciones de productores sobre los que forman parte de ellas, sino en un registro aparte de las mismas características, que recoja los miembros con un periodo de adhesión inferior a tres años, b) Dichos miembros no computarán a efectos del número mínimo de miembros productores y de valor de producción comercializable, c) el valor de su producción no podrá representar más del 20 por cien del valor de la producción total de la organización, d) no podrán suponer más del 20 por cien de los miembros totales de la organización y, finalmente, e) ni ellos ni sus explotaciones podrán estar en estas circunstancias de adhesión en una organización más de dos años de cada seis. Cada organización de productores determinará, asimismo, el plazo de aviso previo para que los miembros productores comuniquen por escrito la renuncia a su calidad de miembros tomando como referencia el plazo de preaviso máximo, de seis meses ${ }^{33}$.

Es cierto que tal exigencia puede frenar el interés del productor por su integración en una OPFH y quizás ha debido considerarse la posibilidad de flexibilizar más su régimen jurídico. Pero sin duda han de conciliarse las exigencias de reconocimiento como OPFH y los controles periódicos de tal cumplimiento, conforme artículo 24 del Real Decreto 532/2017, ya que en otro caso podría peligrar el reconocimiento y su funcionamiento como OPFH. En favor de tal flexibilización, concluido el período mínimo de adhesión se ha de dar de baja, de forma inmediata, a los miembros que lo solicitan pudiendo quedar

31 Asimismo, "los estatutos de la cooperativa o de la sociedad agraria de transformación que posean sección de frutas y hortalizas, deberán establecer que las decisiones relativas al reconocimiento, al funcionamiento y a las actuaciones como organización de productores, incluidas las relativas a la presentación y ejecución de programas operativos y constitución de los fondos operativos establecidos en los artículos 32 y 33 del Reglamento (UE) núm. 1308/2013, del Parlamento Europeo y del Consejo, de 17 de diciembre de 2013, serán adoptadas directamente por la asamblea de la sección", artículo 4.1,f,1 ${ }^{\circ}$ del Real Decreto 532/2017.

32 El artículo 7.1 del Real Decreto $1972 / 2008$, sobre reconocimiento de organizaciones de productores de frutas y hortalizas reguló el mismo período mínimo de adhesión.

33 Dicho plazo máximo de preaviso está regulado en el artículo 6.2 del Reglamento Delegado (UE) 891/2017 de la Comisión, de 13 de marzo de 2017, dejando que sean los Estados miembros los que lo determinen que, como ha quedado descrito, deja su determinación en el ámbito estatutario de la organización de productores. El artículo 11 Real Decreto 532/2017 regula, asimismo, la posibilidad de posponer la baja del miembro productor cuando dicho miembro deba realizar algún reintegro derivado de un programa operativo. 
condicionado únicamente a la devolución de algún reintegro en el marco de los programas operativos de la $\mathrm{OPFH}$, debiendo para ello cumplir con las obligaciones derivadas del programa operativo, salvo autorización expresa del propia $\mathrm{OPFH}$, artículo 11. 2 y 3 del Real Decreto 532/2017.

En segundo lugar, respecto del control democrático de las organizaciones de productores, el artículo 13 del Real Decreto 532/2017 establece, dentro del margen delimitado por el artículo 17 del Reglamento Delegado (UE) 2017/891, el porcentaje máximo de derechos de voto y de capital que cualquier persona física o jurídica puede poseer en una OPFH. Dicho control no será preciso realizarlo en aquellas OPFH que poseen una estructura jurídica que exija la rendición de cuentas democrática. Así, en las cooperativas y secciones de ellas salvo en el caso de miembros agregadores que formen parte de ellas y posean una personalidad jurídica distinta a la de cooperativa o sección de ellas amparada por una norma jurídica que implique su funcionamiento democrático.

En otro caso, ninguna persona física o jurídica podrá poseer el control, directo o indirecto, de más del 34 por cien del total de derechos de voto en cualquier tipo de decisiones de la organización de productores, ni más del 49 por cien del capital social de la misma, ya sea de una manera directa o indirecta. Dichos porcentajes son los exigidos, igualmente, para los miembros agregadores de productores que formen parte de las organizaciones de productores. Además, se establecen reglas especiales que permiten verificar los límites de los derechos de voto y de capital de personas físicas o jurídicas ${ }^{34}$, así como el establecimiento de presunciones de vinculación entre personas físicas o entre personas jurídicas, o de personas físicas con personas jurídicas y viceversa, a efectos de la misma verificación ${ }^{35}$.

De esa forma se arbitra, sin duda, un sistema complejo que exige aportar a los órganos competentes los estatutos de la OPFH y, también, los de todas las entidades que formen parte de la cadena societaria. Ello encuentra sentido en orden

34 De conformidad con el artículo 13.3 Real Decreto 532/2017 "para verificar el límite de los derechos de voto que posee una persona física o jurídica respecto de una entidad de la que forma parte de una manera directa $o$ indirecta, deberán acumularse los derechos de voto respecto de ella que posea directamente o indirectamente a través de personas jurídicas en donde los derechos de voto que tenga le generen una participación mayoritaria; considerándose que posee participación mayoritaria en una entidad si posee el 50 por cien o más de los derechos de voto o del capital social de la misma, en cuyo caso se le asignarán todos los derechos de voto de la misma". Por su parte, el apartado 4 del mismo artículo 13 Real Decreto 532/2017, establece que "para determinar si una persona física o jurídica que aparece más de una vez en la cadena societaria de la organización cumple el límite establecido sobre el capital social, deberán acumularse los porcentajes de los capitales sociales, directos e indirectos, que posea respecto de la entidad".

35 En tal sentido, el artículo 13.5 Real Decreto 532/2017, regula que para el cumplimiento de los límites establecidos de derechos de voto y de capital, se presumirá que existe vinculación entre personas físicas, entre personas jurídicas, o de personas físicas con personas jurídicas o a la inversa, debiendo acumularse sus derechos de voto y su capital social como si fueran una única persona física o jurídica a efectos de evitar que se sobrepasen los porcentajes legalmente delimitados, en una serie de supuestos detallados en el mismo precepto, salvo demostración fehaciente en contra de que existe una responsabilidad diferenciada del riesgo empresarial de la explotación de la que son titulares en defensa de los intereses respectivos. La presunción de vinculación se establece en los casos siguientes: “a) En el caso del pupilo respecto del tutor legal o judicial. b) En el caso de copropiedad del capital social de la persona jurídica, como pueden ser herencias yacentes y comunidad de bienes, respecto de los copropietarios entre sí. c) En el caso de descendientes directos menores de edad respecto de uno o los dos padres que tengan la patria potestad; $y$ d) En los matrimonios, respecto de los cónyuges entre sí. En el caso de explotaciones acogidas a la Ley 35/2011, de 4 de octubre, sobre titularidad compartida de las explotaciones agrarias, la representación de la explotación en la organización por la mujer o el hombre se sujetará a lo dispuesto en el artículo 4 de dicha Ley". 
a que sean los propios productores de los productos para los que se concede el reconocimiento los que mantengan el control de la organización y de las decisiones de la OPFH (Ventas, 2017). Al respecto, debe referenciarse la Sentencia del Tribunal de Justicia de la Unión Europea de 6 de marzo de 2012 (en asunto T-23010, España contra Decisión 2010/152/UE de Comisión Europea, de 11 de marzo de 2010), y el Real Decreto 970/2014, de 21 de noviembre, por el que se modificó el artículo 9 del Real Decreto 1972/2008, de 28 de noviembre, sobre reconocimiento de organizaciones de productores de frutas y hortalizas, relativo al control democrático de la organización de productores, para adaptar dicha legislación al, vigente entonces, Reglamento de Ejecución (UE) núm. 543/2011, conforme a la modificación del mismo por el Reglamento Delegado (UE) núm. 499/2014, de la Comisión. Conforme a ello, a efectos del mantenimiento del control de la organización y de las decisiones de la organización en los miembros productores y, especialmente, aun cuando los Estados miembros verifiquen el funcionamiento democrático de una organización de productores, no podrá abstraerse de la identidad de personas físicas o jurídicas que posean capital de los miembros de la $\mathrm{OPFH}$, ya que ello podría dar lugar a que una persona física o jurídica, con una amplia mayoría de capital de los miembros de la organización pudiera ejercer el control y la decisión de la propia organización.

Con ello, por un lado, la exigencia de control democrático se extiende cuando los miembros de la OPFH son personas jurídicas, a las personas físicas o jurídicas que la controlan y, de otro lado, se ha tratado de poner máxima atención en procurar que se respecten los porcentajes relativos al derecho de voto y de tenencia de capital de forma que la presunción de vinculaciones impidiera el reconocimiento de la OPFH cuando por virtud de las mismas se superen tales límites máximos de voto y/o capital, salvo "...demostración fehaciente en contra de que existe una responsabilidad diferenciada del riesgo empresarial de la explotación de la que son titulares en defensa de los intereses respectivos ...", artículo 13.5 del Real Decreto 532/2017.

Además, los porcentajes delimitados de derecho de voto y de capital se reducen respecto de los máximos permitidos por el artículo 17. 2 del Reglamento Delegado (UE) 2017/891, “....inferior al 50 por cien del total de los derechos de voto y al 50 por cien de las acciones o capital" 36 , pudiendo considerarse la opción de rebajar aún más tales porcentajes establecidos en aras del mejor control del funcionamiento democrático.

\section{Consideraciones finales}

El actual marco legal para el reconocimiento como OPFH de entidades jurídicoempresariales ha obedecido a las nuevas exigencias derivadas de la reglamentación

36 Con el régimen del Reglamento (CE) núm. 2200/1996, del Consejo de 28 de octubre de 1996, el poder de decisión de la organización de productores se determinaba en función de las acciones o participaciones de las que fuera titular el productor en la sociedad vinculándose el porcentaje máximo al número de socios. Así, no se podía disponer de más del 40 por cien en organizaciones con número de socios inferior a 15; 33 por cien en organizaciones con número de socios entre 15 y 39; y 20 por cien en organizaciones con número de socios superior a 39 . 
europea y de las interpretaciones de la Comisión Europea a la propia normativa comunitaria, así como a la necesidad de aclarar, simplificar y mejorar su régimen de funcionamiento. La flexibilización operada en materia de reconocimiento se ha visto respaldada por un mayor control de funcionamiento y de cumplimiento de las exigencias como OPFH.

En ese contexto, las cooperativas siguen siendo, en nuestro país, unas de las entidades más proclives a su reconocimiento como OPFH. Dicha forma jurídicoempresarial acoge determinadas especificidades en su conformación que las hacen especialmente adecuadas para el logro del referido reconocimiento (Agricultura y Cooperación, 2017-a), aunque SAT y sociedades mercantiles puedan obtener el mismo reconocimiento ${ }^{37}$.

En tal sentido han de resaltarse los siguientes aspectos esenciales. En primer lugar, respecto del control democrático de su organización obedece, como se ha visto, el reconocimiento automático para las cooperativas encontrándose amparadas, conforme a su propia normativa, por tal exigencia de funcionamiento democrático. Aunque el artículo 17.1 del Reglamento Delegado (UE) 2017/981 hubiese permitido exigir, conforme a lo establecido en la correspondiente legislación nacional aplicable dicho control democrático, sin embargo de conformidad con lo dispuesto en el artículo 13.2 del Real Decreto 532/2017, no habrán de verificarse los porcentajes máximos de derechos de voto y de acciones o capital.

Como se sabe, uno de los Principios Cooperativos que rigen las cooperativas (conforme a la última revisión en XXXI Congreso de la Alianza Cooperativa Internacional, 1995), es el de Gestión Democrática por parte de los socios, no obstante su extensión entre las cooperativas de primer grado y las de segundo o ulterior grado posee distinto alcance, así como en función del tipo de cooperativa de que se trate y del régimen jurídico que les resulte de aplicación (así, Ley 27/1999, de 16 de julio de Cooperativas -artículo 16-, o Ley Autonómica de Cooperativas, correspondiente, Gadea, Sacristán y Vargas, 2009). Tal flexibilidad regulatoria, respecto del alcance del referido Principio, obedece a la misma reformulación de los Principios Cooperativos que no permanecen inertes al contexto actual de mercado y de la función que están llamadas a cumplir las cooperativas (Vargas, 2015).

De ahí que debamos entender como un logro para las cooperativas a efectos del reconocimiento como OPFH, que el reflejo del Principio de Gestión Democrática haya permitido eximirlas del referido control de funcionamiento democrático por ser inherente a su naturaleza jurídica, cuando el Reglamento Delegado hubiese permitido tal verificación y de ahí, también, que compartamos la afirmación de Barrero y Viguera respecto de que la admisión de excepciones y matizaciones al referido Principio han de ser mesuradas, de interpretación restrictiva y sujetas a

37 En el siguiente enlace se encuentra el listado de OPFH reconocidas en España a 1 de mayo de 2017, con referencia a su forma jurídica, en la que destacan las cooperativas, seguidas de SAT y, finalmente, de sociedades mercantiles capitalistas: http://www.mapama.gob.es/es/agricultura/temas/regulacion-de-losmercados/listadoopsmayo2017_tcm7-458373.pdf. Destacan en segundo lugar las SAT conforme al régimen jurídico para el reconocimiento como OPFH, en los términos examinados, aun su peculiar configuración jurídica necesitada de atención por parte del legislador, por lo que remitimos los estudios recientes de Mauleón Méndez, E., y Genovart Balaguer, 2016 y de Mauleón Méndez, 2015. 
límites objetivos, subjetivos o formales, ya que la generalización del voto plural ponderado en el funcionamiento de las cooperativas podría vaciar de contenido la aplicación de dicho Principio, que se erige como seña de identidad de las cooperativas (Barrero y Viguera, 2015) ${ }^{38}$.

Así, encuentra sentido lo dispuesto en el artículo 60 del Reglamento (UE) núm. 1306/2013, del Parlamento Europeo y del Consejo de 17 de diciembre de 2013, sobre la financiación, gestión y seguimiento de la Política Agrícola Común, cuando sanciona que no se reconocerá a ninguna organización de productores que haya obtenido los requisitos de reconocimiento mediante la creación de situaciones artificiales, en concreto, "cuando se produzcan cambios en el tipo de personalidad jurídica en la organización de productores para ser cooperativas con el objetivo de evadir los controles sobre control democrático", artículo 4.3.d del Real Decreto $532 / 2017$.

En segundo lugar, como se ha podido comprobar, para las secciones de las cooperativas se puede solicitar, igualmente, su reconocimiento como OPFH. Tales secciones quedan exentas, igualmente, del referido control de funcionamiento democrático, artículo 13.2 del Real Decreto 532/2017. Lo que sin duda constituye otra manifestación del atractivo de la forma jurídico-empresarial de la cooperativa para su reconocimiento como OPFH. A tal efecto, las secciones constituyen una peculiar forma de organización interna de la cooperativa (artículo 5 Ley 27/1999, de Cooperativas), frente a la dificultad de contar con filiales, para el desarrollo específico de actividades económico-sociales concretas dentro del propio objeto social de la cooperativa, con autonomía de gestión, separación de patrimonio y cuentas de la explotación diferenciada (Gadea, Sacristán y Vargas, 2009). Ello ha posibilitado el reconocimiento como OPFH para las mismas habida cuenta, en muchas ocasiones, de necesidades de orden económico o funcional que aconseja su constitución -bien en el momento de constitución de la cooperativa o bien en un momento posterior, mediante la correspondiente modificación de los estatutos de la cooperativa- (Gadea, 2006).

El principio cooperativo de Puertas Abiertas (Vargas, 2015) juega, también, en favor de tal manifestación. Y es que, siendo consustancial a las cooperativas la baja voluntaria del socio sin embargo suele encontrarse limitada en el tiempo y de ahí la existencia de cláusulas estatutarias que, generalmente, establecen compromisos de permanencia de hasta cinco años y, para ciertas clases de cooperativas, de hasta diez años (Vargas, 2015: 148; Gadea, Sacristán y Vargas, 2009; Pulgar, 2006).

Finalmente, se advierte la simplificación y aclaración en el nuevo régimen jurídico de las OPFH de las circunstancias en las que la aportación de medios o realización de sus actividades, artículo 10 del Real Decreto 532/2017, pueden ser externalizadas o pueden ser realizadas por otras vías (así, filialess, miembros de la asociación de organización de productores, cooperativas de segundo grado etc).

38 Respecto de la presencia del espíritu democrático en las SAT, calificado a priori como dispar, vid., Mauleón Méndez, E., y Genovart Balaguer, 2016 y de Mauleón Méndez, 2015, ya que formando parte de los objetivos y toma de decisiones en las SAT, los estatutos pueden alterar su configuración en la adopción de acuerdos que entrañen obligaciones económicas para los socios en función de un número de votos proporcionales a su participación en el capital social o de voto ponderado en proporcional al volumen de la actividad realizada por el socio en la SAT. 
Con todo, las cooperativas se convierten en la forma jurídica-empresarial más adecuada al reconocimiento como OPFH.

\section{Referencias bibliográficas}

AGRICULTURA Y COOPERACIÓN (2017-a) Reconocimiento europeo a las OPFH. Agricultura y Cooperación, No 299, p. 9.

AGRICULTURA Y COOPERACIÓN (2017-b) Ciertas especialidades de las OPFH cooperativas recogidas en los nuevos Reglamentos sobre reconocimiento de OPs. Agricultura y Cooperación, № 377, p. 9.

Álvarez Coque, J.M.; López-García Usach, T.; Ouabouch, H. y Anido, D. (2012) El futuro de las organizaciones de productores de frutas y hortalizas. Alimentación, Equipos y Tecnología, No 268, pp.16-19.

Amat Llombart, P. (2007) Aspectos jurídicos y de política legislativa de la última reforma de la Organización Común de Mercados en el sector de frutas y hortalizas: el Reglamento 1182/2007, de 26 de septiembre, en http://www.mapama.gob.es/es/ministerio/servicios/informacion/ocm frutas tcm717826.pdf.

Anido Rivas, J.D.; García Álvarez-Coque, J.M. y Ouabouch, H. (2010) El Sector de frutas y hortalizas español y la política agraria común: actualidad y perspectivas en el marco de la Organización Común de Mercados. Agroalimentaria, № 31, Vol. 16, pp.115-139.

ASAJA (2017) Las OPFH deberán de adaptarse al nuevo Reglamento para acogerse a los importes de retirada. Asociación Agraria Jóvenes Agricultores, No 398, p. 22.

Barrero Rodríguez, E. y Viguera Revuelta, R. (2015) El principio de gestión democrática en las sociedades cooperativas. Alcance y recepción. Ciriec-España. Revista Jurídica de Economía Social y Cooperativa, No 27, pp. 175-204.

Colom Gorgues, A.; Florensa Guiu, R.M.; Plana Farran, M. y Samoui, Y. (2017) Las Cooperativas, las Organizaciones de Productores de Frutas y los Programas Operativos. Normativa y Modelo Europeo para mejorar sus resultados y eficiencia. Lex Social, $\mathrm{N}^{\mathrm{o}} 2$, Vol. 7, pp. 205-228.

COMISIÓN EUROPEA (2016) Una asociación entre Europa y los agricultores. La política agrícola común (PAC) de la UE: por nuestra alimentación, nuestro campo y nuestro medio ambiente. En: Comprender las políticas de la Unión Europea: agricultura. Serie folletos divulgativos.

COMUNICACIÓN DE LA COMISIÓN AL PARLAMENTO EUROPEO, AL CONSEJO, AL COMITÉ ECONÓMICO Y SOCIAL EUROPEO Y AL COMITÉ DE LAS REGIONES (2017), El futuro de los alimentos y de la agricultura, en https://ec.europa.eu/agriculture/sites/agriculture/files/future-ofcap/future_of_food_and_farming_communication_es.pdf.

Ferrer Arranz, J.M. (2001) Organizaciones de productores de frutas y hortalizas. ¿Se cubren los objetivos de la OCM?. Agrícola Vergel: Fruticultura, horticultura, floricultura, $\mathrm{N}^{\mathrm{o}}$ 233, pp. 258-267.

Ferrer Arranz, J.M. (2005) Organizaciones de productores, llave de la OCM de frutas y hortalizas. El caso de la Comunidad Valenciana. Estudios Agrosociales y Pesqueros, N $^{\circ}$ 206, pp. 13-32.

Gadea Soler, E. (2006) Las secciones de las cooperativas. En: Pulgar Ezquerra, J. (Dir.) y Vargas Vasserot, C. (coord.). Cooperativas Agrarias y Sociedades Agrarias de Transformación, Madrid, Dykinson, pp. 605-628. 
Gadea, E.; Sacristán, F, y Vargas, C. (2009) Régimen jurídico de la Sociedad Cooperativa del siglo XXI. Realidad actual y propuestas de reforma. Madrid: Dykinson.

Galdeano Gómez, E.; Jaén García, M. y Molina Morales, A. (2002) Adaptación de las Entidades Asociativas para la comercialización de frutas y hortalizas a la actual Política Agraria Comunitaria: La figura de las OPFH. En Lledó Yagüe, F. y Herrera Campos, R. Agricultura ante el tercer milenio, pp. 499-527.

Garrancho, M.J. (2017) El reglamento "Ómnibus", ¿una reforma intermedia de la PAC 2014-2010?. Revista de divulgación europea para Extremadura, № 41, pp. 16-20.

Mauleón Méndez, E. (2015) La sociedad agraria de transformación a la luz de los principios cooperativos de la ACI y de la Ley de Economía Social. Ciriec-España. Revista Jurídica de Economía Social y Cooperativa, No 27, pp. 459-494.

Mauleón Méndez, E. y Genovart Balaguer, F.I., (2016) La inclusión de la sociedad agraria de transformación en la Ley de Economía Social. Pretensión del legislador o realidad en la praxis empresarial. Ciriec-España. Revista Jurídica de Economía Social y Cooperativa, $\mathrm{N}^{\circ}$ 29, pp. 147-184.

MINISTERIO DE AGRICULTURA Y PESCA, ALIMENTACION Y MEDIO AMBIENTE (2015) Informe sobre las organizaciones de productores de frutas y hortalizas (OPFH). Datos de 2009 a 2013. Ministerio de Agricultura y Pesca, Alimentación y Medio Ambiente. Madrid.

Pulgar Ezquerra, J. (2006), La transmisión de la posición de socio y su pérdida: baja y expulsión en las cooperativas agrarias y sociedades agrarias de transformación. En: Pulgar Ezquerra, J. (Dir.) y Vargas Vasserot, C. (coord.). Cooperativas Agrarias y Sociedades Agrarias de Transformación, Madrid: Dykinson, pp. 393-459.

Sánchez Hernández, A. (2015) La Política Agrícola Común de la Unión Europea. Revista de Derecho Agrario y Agroalimentario, No 67, pp. 159-173.

Vargas Vasserot, C. (2015) El principio cooperativo de puertas abiertas (adhesión voluntaria y abierta). Tópico o realidad en la legislación y en la práctica societaria. Ciriec-España. Revista Jurídica de Economía Social y Cooperativa, № 27, pp. 133-174.

Vargas Vasserot, C. (2017) Las Cooperativas ante el reto de la integración. En: Vargas Vasserot, C. (coord.). Retos y oportunidades en la integración de sociedades cooperativas. Actas Curso de Verano, Universidad Internacional de Andalucía, Publicado en abierto, Universidad de Almería, http://repositorio.ual.es/handle/10835/5144. .. .

Ventas Ballesteros, R. (2017) Las OPFH como mecanismos de integración. En: Vargas Vasserot, C (coord.). Retos y oportunidades en la integración de sociedades cooperativas. Actas Curso de Verano, Universidad Internacional de Andalucía, Publicado en abierto, Universidad de Almería, http://repositorio.ual.es/handle/10835/5144. 